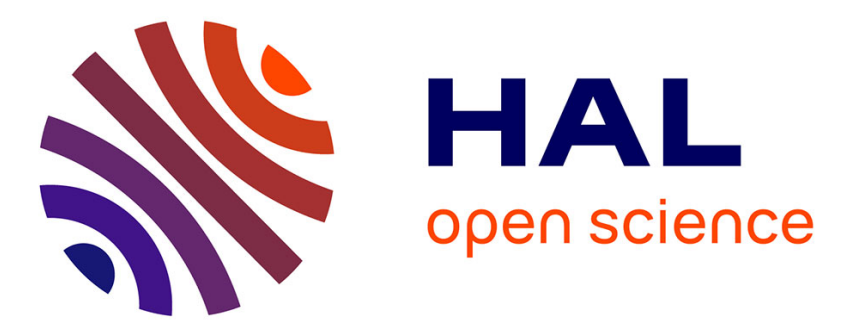

\title{
Phosphinous Acid Platinum Complex as Robust Catalyst for Oxidation: Comparison with Palladium and Mechanistic Investigations
}

\author{
Romain Membrat, Alexandre Vasseur, Alexandre Martinez, Laurent \\ Giordano, Didier Nuel
}

\section{To cite this version:}

Romain Membrat, Alexandre Vasseur, Alexandre Martinez, Laurent Giordano, Didier Nuel. Phosphinous Acid Platinum Complex as Robust Catalyst for Oxidation: Comparison with Palladium and Mechanistic Investigations. European Journal of Organic Chemistry, 2018, 2018 (39), pp.5427-5434. 10.1002/ejoc.201801040 . hal-01905995

\section{HAL Id: hal-01905995 \\ https://hal.science/hal-01905995}

Submitted on 6 Apr 2019

HAL is a multi-disciplinary open access archive for the deposit and dissemination of scientific research documents, whether they are published or not. The documents may come from teaching and research institutions in France or abroad, or from public or private research centers.
L'archive ouverte pluridisciplinaire HAL, est destinée au dépôt et à la diffusion de documents scientifiques de niveau recherche, publiés ou non, émanant des établissements d'enseignement et de recherche français ou étrangers, des laboratoires publics ou privés. 


\title{
Phosphinous Acid Platinum Complex as Robust Catalyst for Oxidation: Comparison with Palladium and Mechanistic Investigations
}

\author{
Romain Membrat, ${ }^{[\mathrm{a}]}$ Alexandre Vasseur, ${ }^{[\mathrm{a}]}$ Alexandre Martinez, ${ }^{*[\mathrm{a}]}$ Laurent Giordano, $^{*[\mathrm{a}]}$ and \\ Didier Nuel*[a]
}

Abstract: Secondary phosphine oxides proved to be effective preligands to stabilise a hydroxy-platinum based catalyst that allows the aerobic/anaerobic oxidation of challenging substrates. Kinetic comparisons showed that this system is more efficient and stable than previously reported similar palladium- based catalysts. A neutral platinum dimer bearing bridging hydroxy ligands has been isolated and fully characterised by $\mathrm{X}$-ray diffraction and its involvement in the mechanism has been evidenced by mechanistic studies.

\section{Introduction}

The design of robust metal complexes able to give raise to long life catalysts efficient in mild conditions and avoiding degrada- tion is still a challenging research objective. In this respect, the chemoselective oxidation of alcohols under mild conditions arouse a great interest in the chemists community involved in organometallic chemistry ${ }^{[1,2]}$ enegised by the difficulty

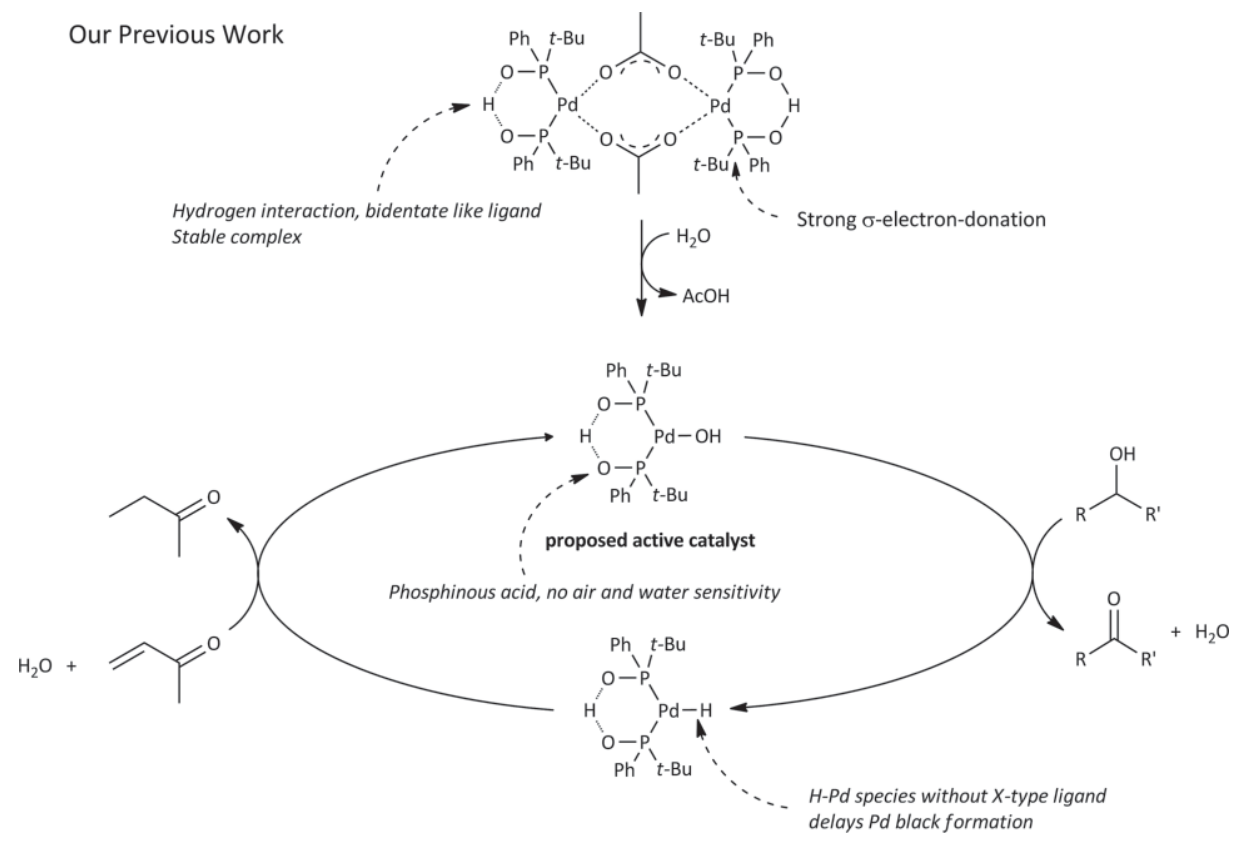

Scheme 1. Alcohols oxidation: proposed strategy to retard black Pd deposit.

[a] Aix-Marseille Univ, Centrale Marseille, CNRS, 13397, Marseille, CNRS, iSm2 UMR 7313,

France.

E-mail: didier.nuel@centrale-marseille.fr alexandre.martinez@centrale-marseille.fr laurent.giordano@centrale-marseille.fr http://ism2.univ-amu.fr/fr/annuaire/chirosciences/nueldidier of such a study goal. The use of palladium(II)-based catalysts ${ }^{[3]}$ in combination with oxygen ${ }^{[4-6]}$ has driven the design of welldefined complexes for achieving highly selective oxidation of alcohols. ${ }^{[7-9]}$ Although remarkable achievements have been witnessed, the main issue in these reactions still remains the catalyst degradation. In a recent work, we demonstrated that a way to tackle this problem lies in the use of secondary phos- 
phine oxides (SPOs) as efficient pre-ligands to stabilise palladium(II) species thus retarding the black palladium deposit (Scheme 1). ${ }^{[10]}$ This particular stability can be attributed to (a) the use of air and water insensitive PA ligands, (b) the hydrogen interaction bonding the two PA ligands leading to a bidentate like that provides a chelate effect, (c) the excellent $\sigma$ electron-donating properties of this particular type of phosphine that greatly stabilise the Pd" species and finally (d) the formation of a palladium hydride that contains no other $\mathrm{X}$ ligand, which thus prevents the reductive elimination and therefore the palladium black formation. Although providing somewhat ground-breaking results, our palladium-based system required relatively elevated temperature and was not compatible with peculiar substrates such as 1,2-diols, 1,3-diols ${ }^{[1,11]}$ and amino alcohols. In this context, recently, the use of additives such as styrene has been proved beneficial for these purposes. ${ }^{[12]}$ Having in mind that platinum hydride are easily formed and stable complexes, ${ }^{[13,14]}$ we anticipated that a platinum based catalytic system similar to our palladium one could be more efficient and would possibly allow to work at lower temperature.

Thus, we report herein a platinum-based catalytic system both highly efficient for the oxidation of notoriously difficult substrate classes and operating under mild conditions. Furthermore, we provide mechanistic insights and striking evidence of the involvement of hydroxy-platinum complex in the catalytic process as well as the full characterisation of its dimer.

\section{Results and Discussion}

We compared the catalytic activities of phosphinous acid (PA) coordinated platinum(II) complexes [(PA)-Pt"] with palladium analogues [(PA)-Pd"] in oxidation reactions of alcohols. In order to assess the potential of such a species, we turned our attention towards a class of compounds particularly resistant to oxidation as target substrates, namely $\mathrm{N}$-alkyl-2,2,6,6-tetramethylpiperidin-4-ols which were weakly reactive in our palladium catalysed system. Moreover, they are of particular interest as their corresponding ketones are added-value compounds. Indeed, they are largely used for their antioxidant and stabilizing properties in polymer chemistry ${ }^{[15-18]}$ and are also useful in carbon dioxide removal from gas steaming in industrial chemical processes. ${ }^{[19-21]}$

\subsection{Catalysts Comparison}

We used as a bench marking reaction the oxidation of the challenging substrate $\mathbf{2} \mathbf{a}^{\left[{ }^{11]}\right.}$ We compared the activities of the two palladium-based catalysts [(PA)-Pd" $] \mathbf{1 a}-\mathbf{b}$ and the platinumbased catalyst 1c (Scheme 2). This selection can be rationalized

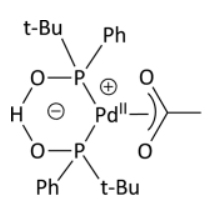

1a

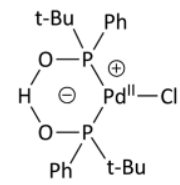

1b

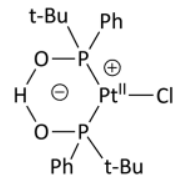

1c

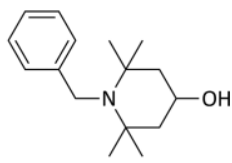

2a
Scheme 2 . Studied catalysts precursors and model substrate. by the following reasons (i) 1 a was previously highlighted as a precursor of hydroxy-palladium species efficient for the oxidation of alcohols ${ }^{[10]}$ (ii) Compared to $\mathbf{1} \mathbf{a}$ or $\mathbf{1} \mathbf{b}, \mathbf{1} \mathbf{c}$ should exhibit a slightly better oxophilicity, ${ }^{[22]}$ and could therefore be promising. The results are presented in Table 1.

Table 1. Comparison of catalysts activity. ${ }^{[a]}$

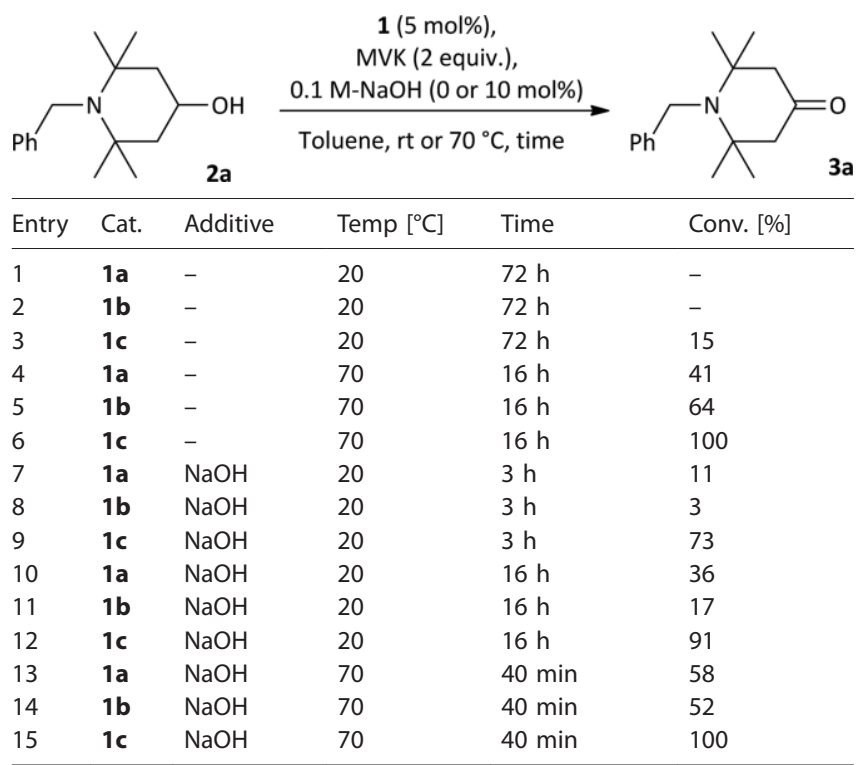

[a] Conditions: 2a (0.6 mmol), Methyl Vinyl Ketone (MVK) (1.2 mmol), 1 (5 mol-\%), when used: $0.1 \mathrm{M}-\mathrm{NaOH}(10 \mathrm{~mol}-\%)$, toluene $(6 \mathrm{~mL})$.

Although all the tested catalysts appeared to be efficient in neutral medium at $70{ }^{\circ} \mathrm{C}$ at first sight, only 1c furnished a partial conversion at room temperature and a total conversion in $16 \mathrm{~h}$ (Table 1 entries 1-6). It is worth noticing that the addition of sodium hydroxide (10 mol-\% relative to substrate) proved to be highly beneficial in all cases (Table 1, entries 7-15). But here again, only $\mathbf{1} \mathbf{c}$ led to a satisfactory conversion at room temperature irrespective of the considered reaction time (Table 1, entry 7-12) and a complete conversion in 40 minutes at $70{ }^{\circ} \mathrm{C}$ (Table 1, entry 13-15). It should be stressed that adding $\mathrm{NaOH}$ allowed reaching a nearly total conversion at room temperature when 1c was used (Table 1, entry 12), the total conversion being attained in $24 \mathbf{~ h}$. While $\mathbf{1 a}$ and $\mathbf{1} \mathbf{b}$ were inactive in the absence of $\mathrm{NaOH}^{[23]}$ the use of $1 \mathrm{c}$ revealed a 30 min-induction period which could be attributed to the time required for the conversion of the inactive precatalyst 1c into an active species. This induction period can be drastically reduced either by increasing the temperature or by adding sodium hydroxide or both, in which case the induction period nearly disappears irrespective of the used precatalyst $\mathbf{1}$. As $\mathbf{1 a}$ and $\mathbf{1} \mathbf{b}$ were poorly efficient at room temperature, kinetic studies were performed at $70{ }^{\circ} \mathrm{C}$. The estimated kinetic constant ratios (Figure 1 and Figure in part 5.1 of the $\mathrm{SI}$ ) showed that 1c was eight times faster than $1 \mathrm{a}\left(k_{1} / k_{1 a}=7.38\right)$ in the presence of $\mathrm{NaOH}$ at that temperature. Furthermore, it was also four times faster than $\mathbf{1} \mathbf{b}$ $\left(K_{1 \mathrm{c}} / k_{1 \mathrm{~b}}=4.05\right)$ under the same conditions. Eventually, the $k_{1 c} / k_{1 a}$ ratio was evaluated at 7.73 while the $K_{1 c} / k_{1 b}$ ratio was 2.82 in the absence of $\mathrm{NaOH}$. 

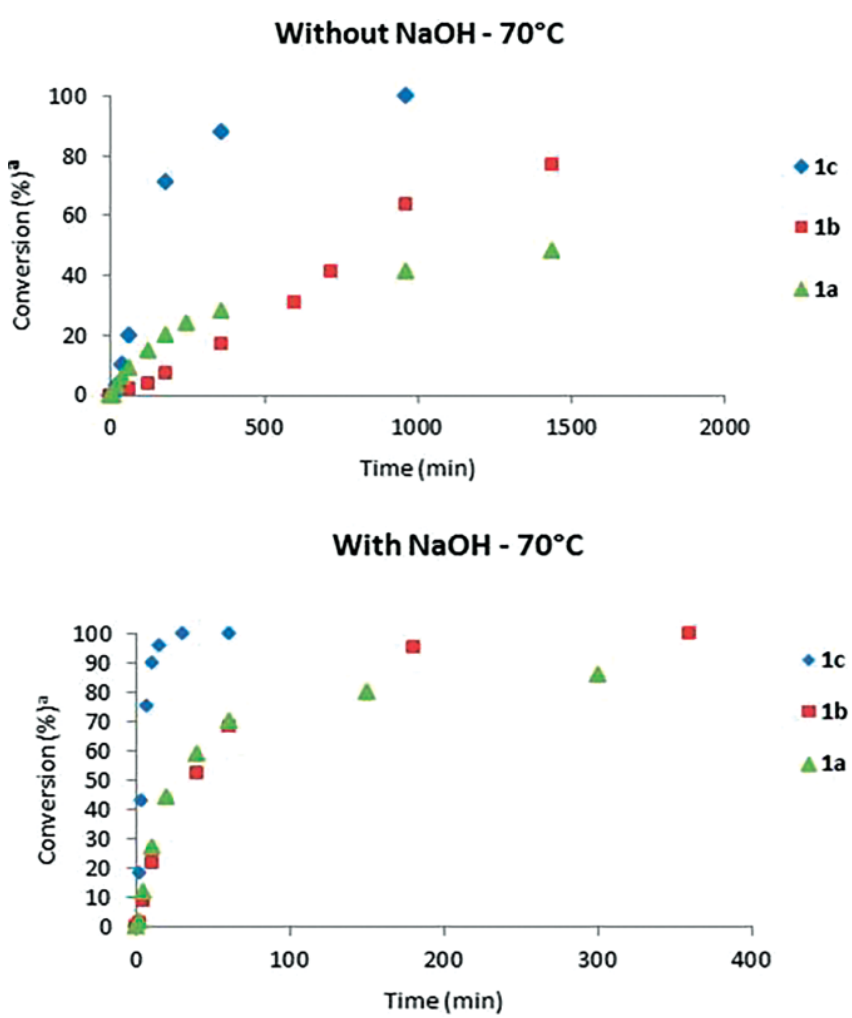

Figure 1. Compared kinetic profiles of the catalytic systems at $70{ }^{\circ} \mathrm{C}$ without (top) or with (bottom) addition of $\mathrm{NaOH}^{[\text {[a] }}$ Conversions were measured by ${ }^{1} \mathrm{H}$ NMR spectroscopy. Profiles obtained by the arithmetic mean of 3 experiments.

\subsection{Scope of the Reaction}

We then examined the scope of our optimised catalytic system. Oxidation reactions of $\mathrm{N}$-Alkyl-2,2,6,6-tetramethyl-piperidin-4-ol derivatives with different substituents at the nitrogen atom, which are not prone to be oxidised through palladium catalysis methods, ${ }^{[1,11]}$ were conducted at room temp. with $1 \mathbf{c}$ as precatalyst and sodium hydroxide as additive $(10 \mathrm{~mol}-\%$ relative to substrate). The results are summarised in Scheme 3.

Notwithstanding the difficulty of such a challenge, ${ }^{[11]} \mathrm{N}$-Alkyl 2,2,6,6-tetramethylpiperidin-4-ols could be oxidised smoothly in our conditions as shown in Scheme 3 (see products $\mathbf{3 a - f}, \mathbf{6 7 -}$ $99 \%$ yield). It is worth noticing that the reaction can be run with a smaller amount of catalyst although with a slight loss of efficiency. For example, 3a was obtained in $75 \%$ yield and $\mathbf{3 f}$ in $50 \%$ yield when using $1 \mathrm{~mol}-\%$ of $1 \mathrm{c}$ in the same conditions. Whereas $\mathrm{N}$-methyl 2,2,6,6-tetramethylpiperidinol was converted into $\mathbf{3 g}$ in an excellent yield (95\%), $\mathbf{3}$ h was obtained in a disappointing $14 \%$. This result clearly highlights the crucial role of all-carbon quaternary centres being positioned adjacent to the nitrogen. This can be attributed to the highly sterically crowded environment of the metal and the restricted number of degrees of freedom associated ${ }^{[24]}$ that prevent the poisoning of the catalyst through coordination of the nitrogen atom to the metal.

Since the oxidation of 1,2- or 1,3- diols into $\alpha$ - or $\beta$-hydroxy ketones respectively is particularly challenging owing to potential metal chelation or competitive reaction, ${ }^{[25,26]}$ we focused

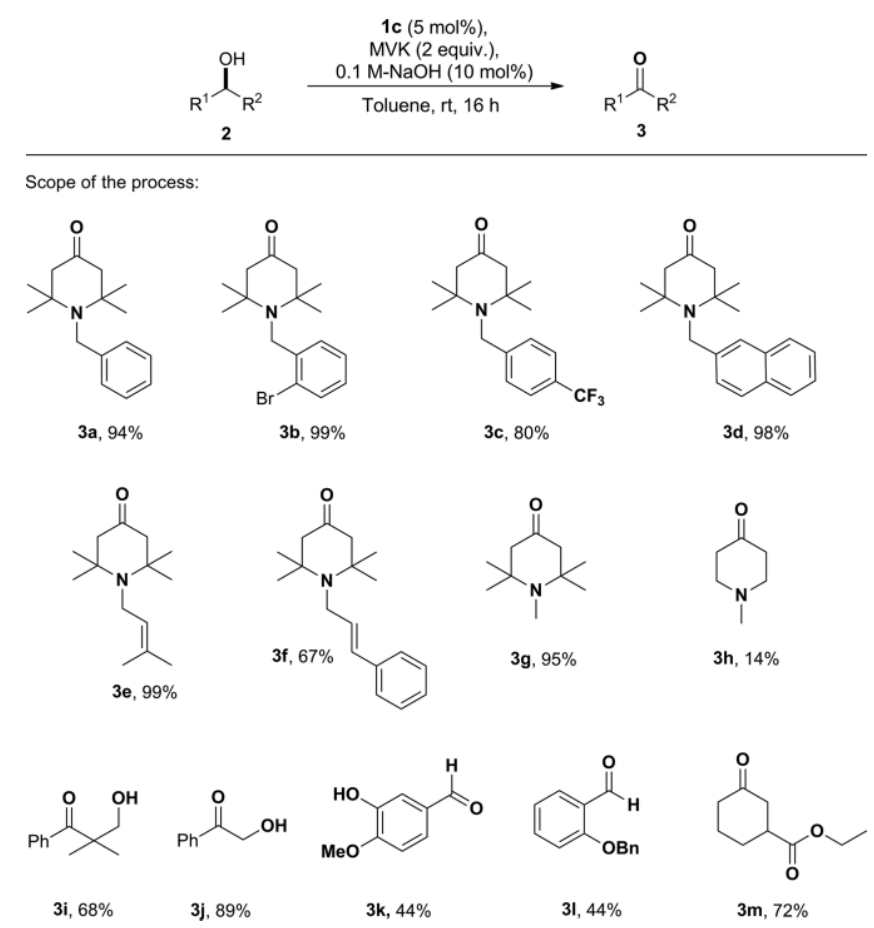

Scheme 3. Scope of the alcohol oxidation using 1c as catalyst precursor. Conditions: alcohol (0.6 mmol), methyl vinyl ketone (MVK) $(1.2 \mathrm{mmol}), 1 \mathrm{c}$ (5 mol-\%), $0.1 \mathrm{M}-\mathrm{NaOH}$ (10 mol-\%), toluene (6 mL), room temp., $16 \mathrm{~h}$.

our efforts on this last challenge. Although some efficient and selective catalytic systems have been proposed to this end, ${ }^{[12,27,28]}$ it should be noted that most of them are based on the use of palladium in combination with nitrogen ligands, ${ }^{[29-31,12,32,33]}$ rather than oxidation-sensitive phosphinetype ligand. To our delight, our method allowed the totally selective oxidation of such substrates in good to excellent yields as evidenced by the compounds $\mathbf{3 i}$ ( $89 \%$ ) and $\mathbf{3 j}$ (68 \%).

Interestingly, our platinum-based conditions proved to be compatible with hydroxyl ethers where similar chelation properties could be expected (see $\mathbf{3 k} \mathbf{k}-\mathbf{l}$ ). Finally, compounds possessing base-sensitive functional groups like esters were also reactive (see $\mathbf{3 m}$ ).

\subsection{Mechanistic Investigations}

To learn more about the nature of the active catalyst, we pursued our mechanistic investigations. In view of the above kinetic studies (Figure 1) and the literature data, ${ }^{[10,11,34,35]}$ we reckoned that the noticed induction period could be ascribed to the time required for the conversion of the inactive $1 \mathrm{c}$ into the dimeric hydroxy-platinum catalyst $\mathbf{4}$ from which the active monomeric specie A would be formed (Scheme 4). We then suggested that the reaction of $\mathbf{A}$ with an alcohol derivative would lead to the corresponding ketone and the hydrido-metal species B, either through the formation of an alkoxy-platinum intermediate followed by a $\beta-\mathrm{H}$ elimination or a metal promoted direct $\mathrm{H}$-abstraction.$^{[36]}$ Coordination of MVK to the metal centre followed by Insertion of its double bond into the $\mathrm{Pt}-\mathrm{H}$ bond would provide $\mathbf{C}$, in tautomeric equilibrium with the 
Pt-enolate D. Eventually, hydrolysis step of the O-Pt bond of $\mathbf{D}$ would deliver the hydrogenated acceptor $\mathrm{H}_{2} \mathrm{MVK}$ and the active catalyst species $\mathbf{A}$. it should be noted that no PA ligand decoordination was observed during the process. ${ }^{[37]}$
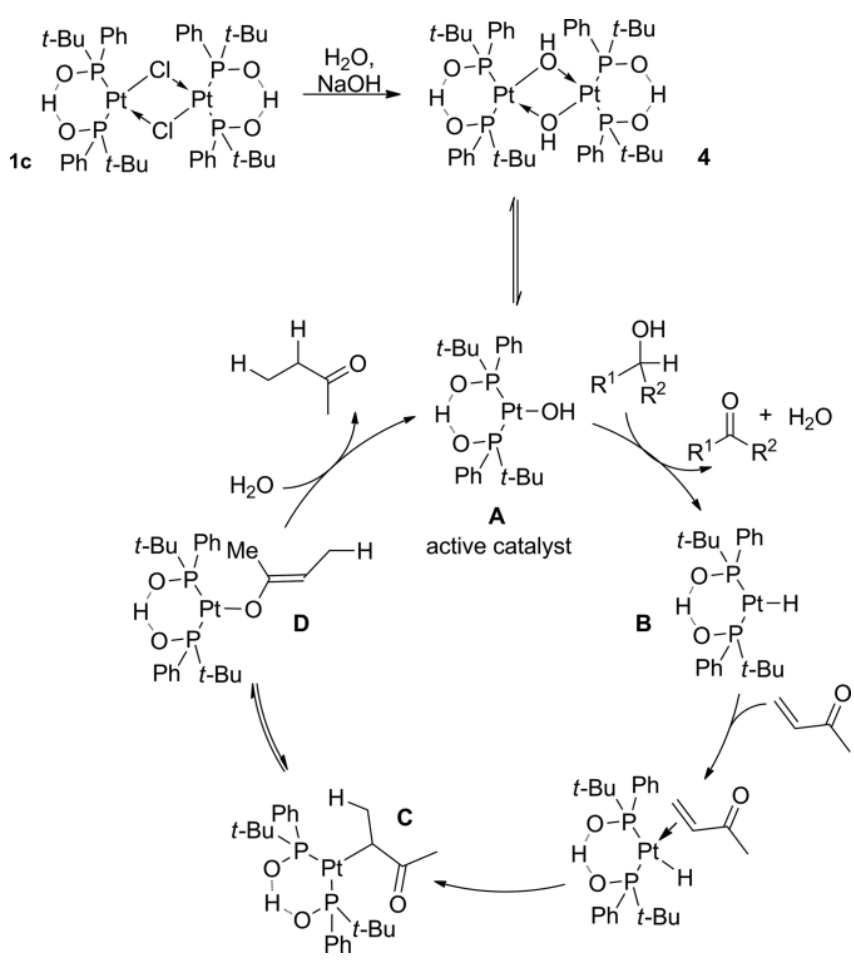

Scheme 4. Proposed mechanism for the platinum-catalysed oxidation of alcohols.

Although seldom demonstrated, hydroxy-metal species are often suspected to be active in such a transformation when an aqueous medium is used. ${ }^{[11]}$ As a consequence, it appeared clear to us that synthesising, characterising and testing this up till now putative complex $\mathbf{4}$ was essential. It should be noted that quite a few hydroxy-platinum dimers bearing mono- ${ }^{[38-45]}$ or di-phosphine ${ }^{[46-49]}$ ligands have been already reported. Nevertheless, to the best of our knowledge none has been made with SPOs as preligands. The reaction of platinum chloride with SPOs in our conditions led to the formation of a mixture of products (see ${ }^{31} \mathrm{P}$ NMR spectra in SI) containing one major compound ( $\delta=61.5 \mathrm{ppm}$ in ${ }^{31} \mathrm{P}$ NMR). Unfortunately, we were unable to isolate it. As we suspected it may be the hydroxyl derivative, we sought for an alternative method which would allow us to synthesise and characterise this compound and confirm (or not) this hypothesis.

Direct treatment of $\mathbf{1 c}$ by sodium hydroxide or $\mathrm{NBu}_{4} \mathrm{OH}$ in dichloromethane at reflux gave only decomposition of the starting material whereas no reaction occurred at room temperature. Trivial treatment of 1c with silver or sodium tetrafluoroborate should be proscribed as this might result in the replacement of the proton linking the PA ligands by a $\mathrm{BF}_{2}$ unit. ${ }^{[50-53]}$ Using $\mathrm{AgNO}_{3}$ to remove the chloride ligands of $\mathbf{1 c}$ resulted in a complex mixture of compounds. We then turned toward an

approach adapted from the one proposed by Sodeoka's group for the synthesis of a dihydroxypalladium dimer, ${ }^{[54]}$ namely using silver hexafluorophosphate as the chloride abstractor to avoid any hydrogen abstraction (Scheme 5).
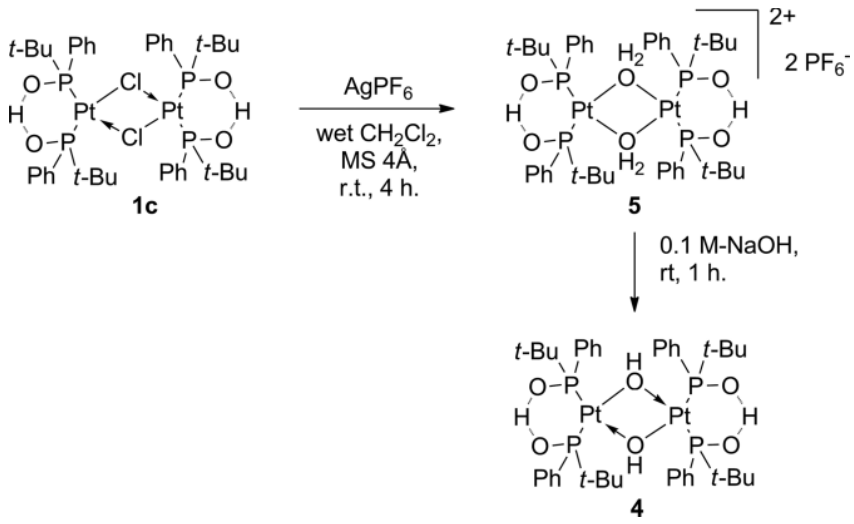

Scheme 5. Synthesis of the hydroxyl platinum dimer 4.

Thus, the reaction of $1 \mathbf{c}$ with $\mathrm{AgPF}_{6}$ was carried out in wet dichloromethane in the presence of molecular sieves. The cationic intermediate $\mathbf{5}$ was thereafter obtained after filtration through celite $\odot$ followed by purification. Subsequent treatment of the latter by diluted sodium hydroxide $(0.1 \mathrm{M})$ led to the formation of $\mathbf{4}$ as the major product in $56 \%$ isolated yield after crystallisation. ${ }^{1} \mathrm{H}$ NMR analysis showed a resonance at $\delta=$ $-0.8 \mathrm{ppm}$ corresponding to the proton of the $\mathrm{OH}$ group. The ${ }^{31} \mathrm{P}$ NMR spectrum of compound $\mathbf{4}$ exhibited a resonance peak at $\delta=61.6 \mathrm{ppm}$ in agreement with the chemical shifts observed for similar complexes ${ }^{[55]}$ and the large Pt-P coupling constant of $5063 \mathrm{~Hz}$ is consistent with the phosphorus atoms in cis position. ${ }^{[56,57]}$ This also confirmed that the major phosphorus containing product in our reaction is the expected hydroxyl platinum compound. The absence of any signal for the $\mathrm{PF}_{6}$ anion $(\delta=146 \mathrm{ppm})$ confirmed that complex 4 is neutral and it is, to the best of our knowledge, the first neutral complex of this type. This is due to the particular bidentate-like form of the phosphinous acid ligands that provided an intramolecular anion. Careful crystallization in hexane/DCM mixture (2 layers) gave crystals of $\mathbf{4}$ suitable for X-ray diffraction analysis (Figure 2). ${ }^{[58]}$ The two platinum centres present a square-planar geometry although the dihedral angles Pt-O-Pt-P exhibit a very slight tetrahedral distortion [maximum deviation from the mean plane of $0.02 \AA]$. The distance between the two metal centres $(3.328 \AA$ ), the average Pt-O bond length of $2.130 \AA$ as well as O-Pt-O angles are similar to those observed in hydroxylbridged dinuclear complexes without metal-metal interaction (Table 2). ${ }^{[39,40,47,49]}$

Likewise, $\mathrm{P}-\mathrm{Pt}-\mathrm{P}$ angles values are consistent with those reported for similar complexes bearing either $\mathrm{PAs}^{[59-62]}$ or bidentate phosphines ${ }^{[4,12-14]}$ as ligands. Finally, the short distances between the two oxygen atoms of the PA ligands $[\mathrm{O}(1) \mathrm{O}(2)$ : $2.389 \AA, \mathrm{O}(5) \mathrm{O}(6): 2.398 \AA$ ] suggest a strong $\mathrm{H}-\mathrm{O}-\mathrm{H}$ bonding. ${ }^{[63]}$ Accordingly, all $\mathrm{P}-\mathrm{O}$ bond lengths are of similar values [in the range $1.5224(10)-1.553(10) \AA]^{[64]}$ and are significantly longer than $\mathrm{P}=\mathrm{O}$ distances $(1.48-1.50 \AA) .{ }^{[65,66]}$ 


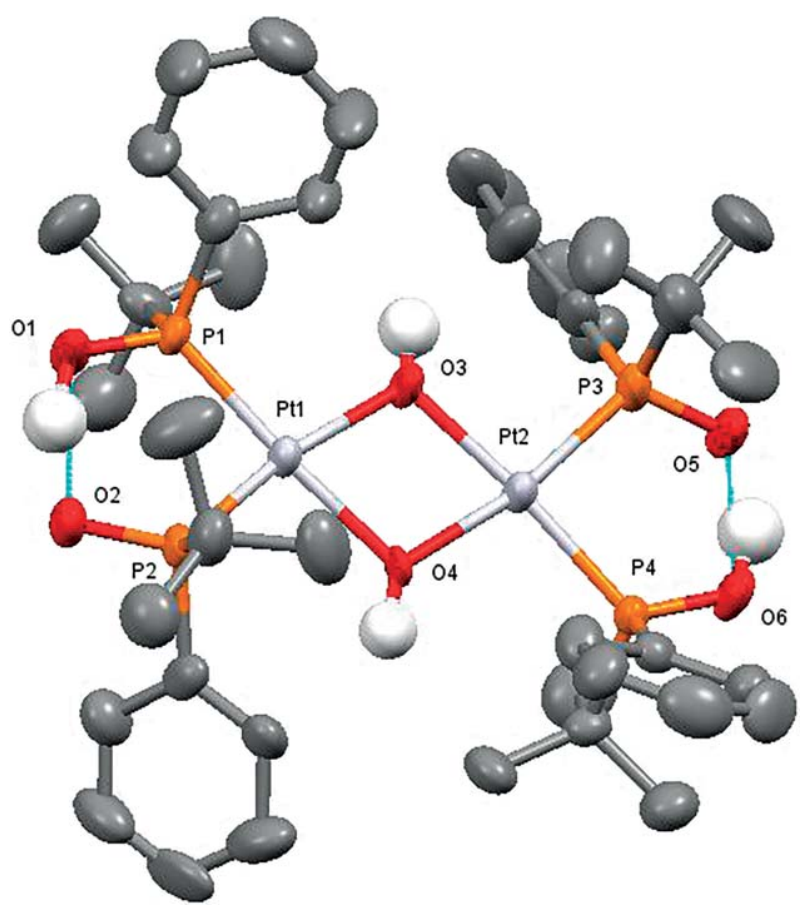

Figure 2. Ellipsoid plot of the X-ray structure of $\mathbf{4}$ - only polar hydrogen are shown.

Table 2. Selected bond lengths $[\AA]$ and angles $\left[^{\circ}\right]$ for 4 . Estimated standard deviations in parentheses.

\begin{tabular}{ll|ll}
\hline $\mathrm{Pt}(1)-\mathrm{P}(1)$ & $2.232(3)$ & $\mathrm{O}(4)-\mathrm{Pt}(1)-\mathrm{P}(1)$ & $174.6(3)$ \\
$\mathrm{Pt}(1)-\mathrm{P}(2)$ & $2.227(4)$ & $\mathrm{O}(4)-\mathrm{Pt}(1)-\mathrm{P}(2)$ & $93.9(3)$ \\
$\mathrm{Pt}(1)-\mathrm{O}(3)$ & $2.146(10)$ & $\mathrm{O}(4)-\mathrm{Pt}(1)-\mathrm{O}(3)$ & $76.8(4)$ \\
$\mathrm{Pt}(1)-\mathrm{O}(4)$ & $2.131(9)$ & $\mathrm{P}(3)-\mathrm{Pt}(2)-\mathrm{P}(4)$ & $91.59(14)$ \\
$\mathrm{Pt}(2)-\mathrm{P}(3)$ & $2.234(4)$ & $\mathrm{O}(3)-\mathrm{Pt}(2)-\mathrm{P}(3)$ & $92.8(3)$ \\
$\mathrm{Pt}(2)-\mathrm{P}(4)$ & $2.245(3)$ & $\mathrm{O}(3)-\mathrm{Pt}(2)-\mathrm{P}(4)$ & $175.1(3)$ \\
$\mathrm{Pt}(2)-\mathrm{O}(3)$ & $2.103(9)$ & $\mathrm{O}(3)-\mathrm{Pt}(2)-\mathrm{O}(4)$ & $77.5(4)$ \\
$\mathrm{Pt}(2)-\mathrm{O}(4)$ & $2.140(9)$ & $\mathrm{O}(4)-\mathrm{Pt}(2)-\mathrm{P}(3)$ & $168.9(3)$ \\
$\mathrm{P}(1)-\mathrm{O}(1)$ & $1.553(10)$ & $\mathrm{O}(4)-\mathrm{Pt}(2)-\mathrm{P}(4)$ & $98.3(3)$ \\
$\mathrm{P}(2)-\mathrm{O}(2)$ & $1.538(11)$ & $\mathrm{O}(1)-\mathrm{P}(1)-\mathrm{Pt}(1)$ & $116.6(4)$ \\
$\mathrm{P}(3)-\mathrm{O}(5)$ & $1.550(12)$ & $\mathrm{O}(2)-\mathrm{P}(2)-\mathrm{Pt}(1)$ & $117.7(5)$ \\
$\mathrm{P}(4)-\mathrm{O}(6)$ & $1.524(10)$ & $\mathrm{O}(5)-\mathrm{P}(3)-\mathrm{Pt}(2)$ & $117.5(5)$ \\
$\mathrm{P}(2)-\mathrm{Pt}(1)-\mathrm{P}(1)$ & $91.43(14)$ & $\mathrm{O}(6)-\mathrm{P}(4)-\mathrm{Pt}(2)$ & $116.9(4)$ \\
$\mathrm{O}(3)-\mathrm{Pt}(1)-\mathrm{P}(1)$ & $97.9(3)$ & $\mathrm{Pt}(2)-\mathrm{O}(3)-\mathrm{Pt}(1)$ & $103.2(5)$ \\
$\mathrm{O}(3)-\mathrm{Pt}(1)-\mathrm{P}(2)$ & $169.7(3)$ & $\mathrm{Pt}(1)-\mathrm{O}(4)-\mathrm{Pt}(2)$ & $102.4(4)$ \\
\hline
\end{tabular}

In order to demonstrate that $\mathbf{4}$ is actively involved in the catalytic cycle, we studied its activity toward our model substrate $\mathbf{2 a}$ in our optimised conditions. Firstly, we observed that 4 led to complete conversion in $16 \mathrm{~h}$ at room temperature. A closer look at the results showed that 1 c requires a short $(<5$ minutes) induction time (Figure 3) while $\mathbf{4}$ was immediately active and more efficient than $1 c\left(k_{4} / k_{1 C}=2\right)$ in the early stages of the reaction. This difference could be due to the time required to convert the inactive $\mathbf{1 c}$ into the active $\mathbf{4}$ and therefore to a low concentration of active species.

In our mechanism suggested in Scheme 4, water would be produced through the oxidation of the alcohol on one hand, and 4 would be delivered by reaction of $1 c$ with water on the other hand. Therefore, if $\mathbf{4}$ actually resulted from $\mathbf{1 c}$, it would be active in a dry medium. We thus performed kinetic studies of the same reaction using dry toluene as the sole solvent (Fig-

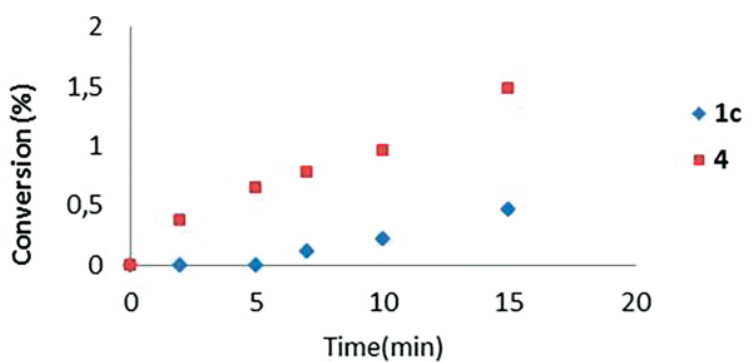

Figure 3. Compared kinetic profiles of the reaction at room temperature using 1c or $\mathbf{4}$ in early times of the reaction - conversions were measured by ${ }^{1} \mathrm{H}$ NMR spectroscopy. Profiles obtained by the arithmetic mean of 3 experiments.

ure 4). It appeared that $\mathbf{4}$ was indeed appreciably active in dry medium while 1c proved to be totally inactive even though the former afforded only a $20 \%$ conversion after a 45 h-time reaction. Adding water (1:8 v/v $\mathrm{H}_{2} \mathrm{O} /$ toluene) proved very slightly beneficial with both complexes while the addition of sodium hydroxide allows to recover a good activity. This clearly showed that $\mathbf{4}$ is not only the active hydroxyl monomer species but also the outcome of the reaction of the precatalyst 1c with sodium hydroxide.

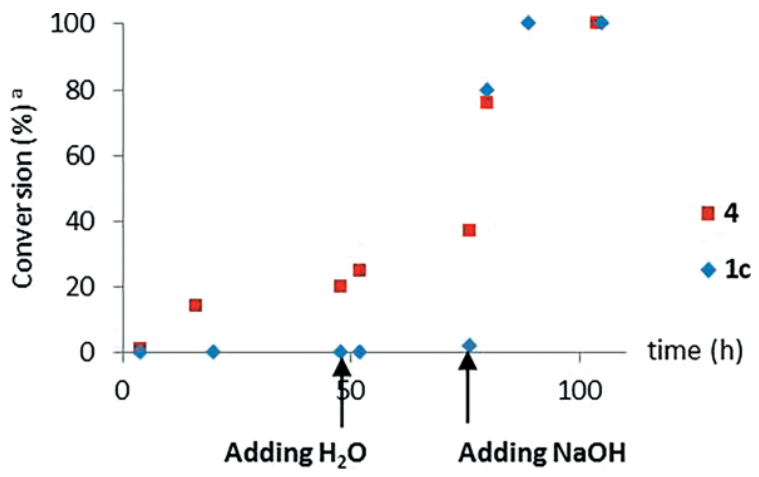

Figure 4. Effects of adding water and then $\mathrm{NaOH}$ at room temperature.

Another evidence of the involvement of $\mathbf{4}$ in the catalytic process is given by the ${ }^{31} \mathrm{P}$ NMR spectrum of the crude material at the end of the reaction. ${ }^{[67]}$ Starting with $\mathbf{1 c}$ led to a complex mixture of phosphorus-containing compounds among which $\mathbf{4}$ could be detected. In contrast, using well-defined $\mathbf{4}$ as the catalyst led to a much cleaner reaction and $\mathbf{4}$ was the major complex detected at the end of the reaction.

Moreover, other information could be extracted from those studies. Indeed, the regeneration of the active catalytic species and production of the reduced Michael acceptor could proceed through two pathways. The first one could involve a hydrolysis step from D (Scheme 6 path a) while the second one would consist in a ligand exchange between a free $\mathrm{OH}^{-}$and the enolate ligand in $\mathbf{D}$ (Scheme 6 path b). When $\mathbf{4}$ was used, the addition of water led to a slight acceleration of the reaction while adding $\mathrm{NaOH}$ greatly enhanced the rate. As, in this case, the active platinum hydroxyl species is already formed, this result tends to demonstrate the involvement of the hydroxide ion in 
the regeneration step of the active catalytic species and highlights the path $b$ as the major route.

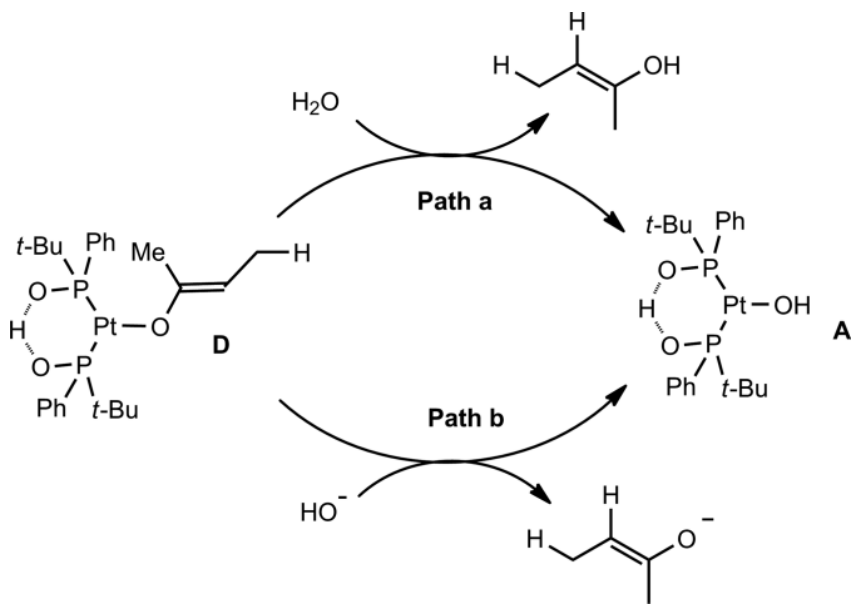

Scheme 6. Possible paths for the regeneration of $\mathbf{A}$.

\section{Conclusions}

In conclusion we have developed a new very stable SPO platinum based catalyst particularly efficient in the oxidation of highly challenging substrates working in weakly basic medium at room temperature. This efficiency clearly demonstrates that the phosphinous acid ligands greatly stabilise the metal complex, thus retarding the catalyst degradation and the black metal deposit. We have also isolated and fully characterised the first hydroxyplatinum dimer bearing phosphinous acid ligands and obtained strong evidence of its implication in the anaerobic oxidation of alcohols. The easy availability of the $[\mathrm{Pt}](\mu-\mathrm{OH})$ 4 would allow us to explore a new broad field of metal-catalyzed reaction, including asymmetric versions or $\mathrm{C}-\mathrm{C}$ bonds forming reactions.

\section{Experimental Section}

2.1. General Information: All solvents were purified by standard procedures or obtained from a Solvent Purification System (Braun SPS 800). Unless otherwise mentioned all reactions were carried out under an atmosphere of dry argon. Commercial organic reagents were purchased from ALDRICH and used without further purification. Analytical Thin layer chromatography (TLC) was carried out on Merck silica gel 60 F254 and product were revealed under ultraviolet light (254 $\mathrm{nm}$ and $366 \mathrm{~nm}$ ), or stained with dyeing reagent solutions as $5 \%$ phosphomolybdic acid solution, potassium permanganate solution or $p$-anisaldehyde solution in ethanol followed by gentle heating. Preparative Flash chromatography was performed with Merck silica gel 60 (230-400Mesh) unless otherwise mentioned. ${ }^{1} \mathrm{H},{ }^{13} \mathrm{C}$ and ${ }^{31} \mathrm{P}$ spectra were recorded on Bruker Avance III nanobay spectrometers operating at 400 and/or $300 \mathrm{MHz}$. Melting points (uncorrected) were determined in a capillary tube with a Mettler LP61 apparatus. High Resolution MS experiments were performed with a QStar Elite Mass Spectrometer (Applied Biosystems SCIEX, Concord, ON, Canada) equipped with an electrospray ionization (ESI) source. Complexes $1 a^{[68]} 1 b^{[50]}$ and $1 c^{[59]}$ were synthesized according to reported procedures.

\subsection{Syntheses:}

General Procedure for $\mathbf{N}$-Alkylation of 2,2,6,6-Tetramethylpiperidin-4-ol: In a $30 \mathrm{~mL}$ PARR autoclave was introduced the 2,2,6,6tetramethylpiperidin-4-ol $(2.0 \mathrm{~g}, 12.7 \mathrm{mmol})$ and the allyl or benzyl bromide ( 0.5 equiv.) dissolved in dry toluene $(13 \mathrm{~mL})$. The autoclave was sealed and the mixture was heated to $130^{\circ} \mathrm{C}$. After $40 \mathrm{~h}$ whilst stirring, the mixture was diluted in AcOEt and water. The aqueous layer was extracted 3 times with AcOEt $(25 \mathrm{~mL})$ and combined organic layers were washed with water $(20 \mathrm{~mL})$, brine $(20 \mathrm{~mL})$ and dry over $\mathrm{Na}_{2} \mathrm{SO}_{4}$. After concentration under vacuum, the residue was purified by flash chromatography on silica gel using a combination of petroleum ether and ethyl acetate for benzylic compounds and dichloromethane and methanol for allylic derivatives to yield pure desired products. All analytical data are available in ESI.

General Procedure for Catalysed Anaerobic Alcohols Oxidation: In a flame-dried $50 \mathrm{~mL}$ Schlenk tube was introduced under argon atmosphere 1c $(17.7 \mathrm{mg}, 0.03 \mathrm{mmol})$ and $2(0.6 \mathrm{mmol})$ dissolved in dry toluene $(6 \mathrm{~mL})$. Methyl vinyl ketone $(100 \mu \mathrm{L}, 1.2 \mathrm{mmol})$ and 0.1 $\mathrm{M}-\mathrm{NaOH}$ aqueous solution $(0.6 \mu \mathrm{L}, 0.06 \mathrm{mmol})$ were then added to the reaction mixture. The reaction was heated when necessary and stirred for the desired time. Organic layer was separated and aqueous layer was extracted with ethyl acetate $(3 \times 5 \mathrm{~mL})$. Combined organic layers were dried with $\mathrm{Na}_{2} \mathrm{SO}_{4}$ and concentrated under vacuum. The crude resulting product was purified if necessary by column chromatography on silica gel using an appropriated combination of petroleum ether and ethyl acetate to yield pure desired products. More detailed procedure and analytical data are available in ESI.

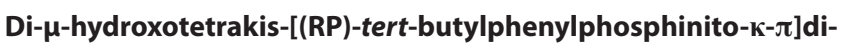
platinate (4): In a $50 \mathrm{~mL}$ flamed dried Schlenk tube under argon atmosphere, di- $\mu$-chlorotetrakys-[tert-butylphenylphosphinito- $\kappa-$ P]diplatinate(2-) 1c (150 mg, $0.25 \mathrm{mmol})$ were dissolved in wet dichloromethane $(20 \mathrm{~mL})$ and molecular sieves $4 \AA$ ( $20 \mathrm{~g})$ were added. $\mathrm{AgPF}_{6}(63 \mathrm{mg}, 0.25 \mathrm{mmol})$, weighted in a glove box was added in one portion and the Schlenk tube was protected from light by aluminium foil. The mixture was stirred at $15{ }^{\circ} \mathrm{C}$ (the temperature must be precisely maintained). After $4 \mathrm{~h}$, the crude mixture was filtered through a short pad of Celite $\odot$ and then on a short pad of no flash silica (elution with $\mathrm{Et}_{2} \mathrm{O}$ ). Volatiles were evaporated and the resulting yellow solid was introduced in a $50 \mathrm{~mL}$ Schlenk tube, dissolved in wet DCM and treated with $0.1 \mathrm{M}-\mathrm{NaOH}$ aqueous solution $(5 \mathrm{~mL})$. After stirring at room temperature for $1 \mathrm{~h}$, the aqueous layer was removed and the organic layer was dried with $\mathrm{Na}_{2} \mathrm{SO}_{4}$ and filtered through a short pad of non-flash silica (elution with $\mathrm{Et}_{2} \mathrm{O}$ ) and concentrated under vacuum in order to obtain the desired complex 4 as a crystalline yellow powder in $56 \%$ yield $(83 \mathrm{mg})$ with a 95:5 meso/dl ratio. Careful recrystallization in hexane/DCM gave small yellow crystals suitable for X-ray Diffraction. Analytical data and cif file (CCDC 1582905) are available in ESI.

CCDC 1582905 (for 1c) contains the supplementary crystallographic data for this paper. These data can be obtained free of charge from The Cambridge Crystallographic Data Centre.

\section{Acknowledgments}

This work was supported by the Ministère de l'Enseignement Supérieur et de la Recherche (R. Membrat Ph.D. grant), the Centre National de la Recherche Scientifique (CNRS), AMU, and Centrale Marseille. We thank Dr. Sabine Michaud-Chevallier for her help in ESI(+)-MS studies, Christophe Chendo and Dr. Valérie 
Monnier for mass spectrometry analyses and Dr. Michel Giorgi for X-ray diffraction analysis and structure determination (Spectropole, Fédération des Sciences Chimiques de Marseille). Umicore AG \& Co. KG is acknowledged for the generous gift of platinum complexes.

[1] J.-E. Bäckvall (Ed.), Modern Oxidation Methods, Wiley-VCH, Weinheim, 2009.

[2] C. Parmeggiani, F. Cardona, Transition Metal Catalysis in Aerobic Alcohol Oxidation, n.d.

[3] M. S. Sigman, M. J. Schultz, Org. Biomol. Chem. 2004, 2, 25512554.

[4] K. M. Gligorich, M. S. Sigman, Chem. Commun. 2009, 3854.

[5] S. S. Stahl, Angew. Chem. Int. Ed. 2004, 43, 3400-3420; Angew. Chem. 2004, 116, 3480-3501.

[6] J. Muzart, Tetrahedron 2003, 59, 5789-5816.

[7] D. C. Ebner, R. M. Trend, C. Genet, M. J. McGrath, P. O'Brien, B. M. Stoltz, Angew. Chem. Int. Ed. 2008, 47, 6367-6370; Angew. Chem. 2008, 120, 6467-6470.

[8] M. S. Sigman, D. R. Jensen, Acc. Chem. Res. 2006, 39, 221-229.

[9] D. R. Jensen, M. J. Schultz, J. A. Mueller, M. S. Sigman, Angew. Chem. Int. Ed. 2003, 42, 3810-3813; Angew. Chem. 2003, 115, 3940-3943.

[10] A. Vasseur, R. Membrat, D. Gatineau, A. Tenaglia, D. Nuel, L. Giordano, ChemCatChem 2017, 9, 728-732.

[11] G. J. Ten Brink, I. W. C. E. Arends, R. A. Sheldon, Adv. Synth. Catal. 2002, 344, 355-369.

[12] W. C. Ho, K. Chung, A. J. Ingram, R. M. Waymouth, J. Am. Chem. Soc. 2018, 140, 748-757.

[13] P. Sgarbossa, A. Scarso, G. Strukul, R. A. Michelin, Organometallics 2012, 31, 1257-1270.

[14] R. A. Michelin, R. Ros, J. Chem. Soc., Dalton Trans. 1989, 1149-1159.

[15] M. Dagonneau, V. B. Ivanov, E. G. Rozantsev, V. D. Sholle, E. S. Kagan, J. Macromol. Sci., Part C 1982, 22, 169-202.

[16] T. Kurumada, H. Ohsawa, O. Oda, T. Fujita, T. Toda, T. Yoshioka, J. Polym. Sci., Part Polym. Chem. 1985, 23, 1477-1491.

[17] H. Zweifel, Stabilization of Polymeric Materials, Springer Berlin Heidelberg, Berlin, Heidelberg, 1998.

[18] G. Kasza, K. Mosnáčková, A. Nádor, Z. Osváth, T. Stumphauser, G. Szarka, K. Czaniková, J. Rychlý, Š. Chmela, B. Iván, J. Mosnáček., Eur. Polym. J. 2015, 68, 609-617.

[19] Z. Idris, D. A. Eimer, Energy Procedia 2014, 51, 247-252.

[20] R. J. Hook, Ind. Eng. Chem. Res. 1997, 36, 1779-1790.

[21] P. M. M. Blauwhoff, G. F. Versteeg, W. P. M. Van Swaaij, Chem. Eng. Sci. 1984, 39, 207-225.

[22] K. P. Kepp, Inorg. Chem. 2016, 55, 9461-9470.

[23] The Table presenting the results of this study and the corresponding figures can be found in the supporting information.

[24] J. P. Das, I. Marek, Chem. Commun. 2011, 47, 4593-4623.

[25] J. B. Arterburn, Tetrahedron 2001, 57, 9765-9788.

[26] A. S. Perlin, in Adv. Carbohydr. Chem. Biochem., Elsevier, 2006, pp. 183250.

[27] G. Noronha, P. M. Henry, J. Mol. Catal. A 1997, 120, 75-87.

[28] L. Bettucci, C. Bianchini, W. Oberhauser, T.-H. Hsiao, H. M. Lee, J. Mol. Catal. A 2010, 322, 63-72.

[29] A. J. Ingram, K. L. Walker, R. N. Zare, R. M. Waymouth, J. Am. Chem. Soc. 2015, 137, 13632-13646.

[30] K. Chung, S. M. Banik, A. G. De Crisci, D. M. Pearson, T. R. Blake, J. V. Olsson, A. J. Ingram, R. N. Zare, R. M. Waymouth, J. Am. Chem. Soc. 2013, 135, 7593-7602.

[31] N. R. Conley, L. A. Labios, D. M. Pearson, C. C. L. McCrory, R. M. Waymouth, Organometallics 2007, 26, 5447-5453.

[32] L. Bettucci, C. Bianchini, J. Filippi, A. Lavacchi, W. Oberhauser, Eur. J. Inorg. Chem. 2011, 1797-1805.
[33] N. D. Vu, B. Guicheret, N. Duguet, E. Métay, M. Lemaire, Green Chem. 2017, 19, 3390-3399.

[34] Y. Tsuchiya, Y. Hamashima, M. Sodeoka, Org. Lett. 2006, 8, 4851-4854.

[35] T. Hara, J. Sawada, Y. Nakamura, N. Ichikuni, S. Shimazu, Catal. Sci. Technol. 2011, 1, 1376-1382.

[36] P. M. Castro, H. Gulyás, J. Benet-Buchholz, C. Bo, Z. Freixa, P. W. N. M. van Leeuwen, Catal. Sci. Technol. 2011, 1, 401-407.

[37] In order to check that there is no de-coordination of the PA ligands we performed control experiments (see SI for details). Firstly, we run a reaction between the free OPS and the MVK in our conditions and found no product (the SPO remains intact). Secondly, complex 1c was stirred with MVK in the same conditions and 1c was recovered at the end of the process. Finally, very thorough analysis of the final crude mixture did not reveal any de-coordination of the ligands during the oxidation reaction of the model substrate $\mathbf{2 a}$.

[38] G. W. Bushnell, K. R. Dixon, R. G. Hunter, J. J. McFarland, Can. J. Chem. 1972, 50, 3694-3699.

[39] G. W. Bushnell, Can. J. Chem. 1978, 56, 1773-1778.

[40] G. Trovo, G. Bandoli, U. Casellato, B. Corain, M. Nicolini, B. Longato, Inorg. Chem. 1990, 29, 4616-4621.

[41] T. K. Miyamoto, Y. Suzuki, H. Ichida, Chem. Lett. 1992, 21, 839-842.

[42] T. K. Miyamoto, Y. Suzuki, H. Ichida, Bull. Chem. Soc. Jpn. 1992, 65, 33863397.

[43] E. Costa, M. Murray, P. G. Pringle, M. B. Smith, Inorg. Chim. Acta 1993, 213, 25-28.

[44] J. J. Li, W. Li, A. J. James, T. Holbert, T. P. Sharp, P. R. Sharp, Inorg. Chem. 1999, 38, 1563-1572.

[45] B. Longato, G. Bandoli, A. Dolmella, Eur. J. Inorg. Chem. 2004, 1092-1099.

[46] C. Pisano, G. Consiglio, A. Sironi, M. Moret, J. Chem. Soc., Chem. Commun. $1991,421-421$.

[47] J. J. Li, W. Li, P. R. Sharp, Inorg. Chem. 1996, 35, 604-613.

[48] U. Anandhi, T. Holbert, D. Lueng, P. R. Sharp, Inorg. Chem. 2003, 42, 1282 1295.

[49] P. Sgarbossa, M. F. C. Guedes da Silva, A. Scarso, R. A. Michelin, A. J. L. Pombeiro, Inorg. Chim. Acta 2008, 361, 3247-3253.

[50] E. Y. Y. Chan, Q.-F. Zhang, Y.-K. Sau, S. M. F. Lo, H. H. Y. Sung, I. D. Williams, R. K. Haynes, W.-H. Leung, Inorg. Chem. 2004, 43, 4921-4926.

[51] R. P. Sperline, D. M. Roundhill, Inorg. Chem. 1977, 16, 2612-2617.

[52] R. P. Sperline, W. B. Beaulieu, D. M. Roundhill, Inorg. Chem. 1978, 17, 2032-2035.

[53] S. G. N. Roundhill, D. M. Roundhill, Acta Crystallogr., Sect. B 1982, 38, 2479-2481.

[54] A. Fujii, E. Hagiwara, M. Sodeoka, J. Am. Chem. Soc. 1999, 121, 54505458.

[55] J. Bigeault, L. Giordano, I. de Riggi, Y. Gimbert, G. Buono, Org. Lett. 2007, 9, 3567-3570.

[56] S. O. Grim, R. L. Keiter, W. McFarlane, Inorg. Chem. 1967, 6, 1133-1137.

[57] C. J. Cobley, P. G. Pringle, Inorg. Chim. Acta 1997, 265, 107-115.

[58] A suitable crystal was selected and mounted on a SuperNova, Dual, Cu at home/near, AtlasS2 diffractometer. The crystal was kept at $293.0 \mathrm{~K}$ during data collection. Using Olex2, ${ }^{[58 a]}$ the structure was solved with the ShelXT ${ }^{[58 \mathrm{~b}]}$ structure solution program using Intrinsic Phasing and refined with the ShelXLc refinement package using Least Squares minimization. Crystallographic data have been deposited to the Cambridge Crystallographic Data Center (CCDC 1582905). a) O. V. Dolomanov, L. J. Bourhis, R. J. Gildea, J. A. K. Howard, H. Puschmann, J. Appl. Crystallogr. 2009, 42, 339-341; b) G. M. Sheldrick, Acta Crystallogr., Sect. A 2015, 71, 3-8; c) G. M. Sheldrick, Acta Crystallogr., Sect. C 2015, 71, 3-8.

[59] T. Achard, L. Giordano, A. Tenaglia, Y. Gimbert, G. Buono, Organometallics 2010, 29, 3936-3950.

[60] L.-B. Han, N. Choi, M. Tanaka, Organometallics 1996, 15, 3259-3261.

[61] J. Bader, R. J. F. Berger, H.-G. Stammler, N. W. Mitzel, B. Hoge, Chem. Eur. J. Chem. Weinh. Bergstr. Ger. 2011, 17, 13420-13423.

[62] N. Allefeld, J. Bader, B. Neumann, H.-G. Stammler, N. Ignat'ev, B. Hoge, Inorg. Chem. 2015, 54, 7945-7952.

[63] D. V. Naik, G. J. Palenik, S. Jacobson, A. J. Carty, J. Am. Chem. Soc. 1974 96, 2286-2288.

[64] D. E. C. Corbridge, Phosphorus Chemistry, Biochemistry and Technology, CRC Press, Boca Raton, 2013. 
[65] G. Annibale, P. Bergamini, V. Bertolasi, E. Besco, M. Cattabriga, R. Rossi, Inorg. Chim. Acta 2002, 333, 116-123.

[66] N. J. Goodwin, W. Henderson, B. K. Nicholson, Inorg. Chim. Acta 2002 $335,113-118$.

[67] The mentioned ${ }^{31} \mathrm{P}$ NMR spectra are available in the supporting information.
[68] J. Bigeault, L. Giordano, G. Buono, Angew. Chem. Int. Ed. 2005, 44, 47534757; Angew. Chem. 2005, 117, 4831-4835. 